\title{
2013 노벨물리학상
}

\section{새로운 에너지에서의 LHC 물리}

DOI: $10.3938 /$ PhiT. 22. 058

\section{김 동 희}

\section{4-TeV LHC}

\section{DongHee KIM}

Since the discovery of the Higgs particle, great expectations have existed that new phenomena may be found at new energies. The LHC is being prepared for an increase in energy to 13 (14) $\mathrm{TeV}$ and for the start of operation a year from now. Here, the physics potentials at the new energy of the LHC will be stressed.

힉스입자의 발견은 표준모형의 완성이라는 측면에서 괄목할 만하다. 그렇다고 표준모형에서 마지막으로 예측되는 입자가 발견되었다고 우리가 우주의 모든 물리적 현상을 이해한 것은 결코 아님은 자명하다. CMS와 ATLAS 실험 그룹은 힉스입자 탐색 연구 토픽을 제외하고도 150 여 가지가 넘는 새로운 형태 의 물리현상을 찾기 위하여 노력하고 있다. 힉스 입자의 발견 은 있을지도 모르는 여러 새로운 물리 현상의 발견에 기폭제 역할을 하고 있다. 당연히 힉스입자를 발견한 $\mathrm{LHC}$ 실험은 탄 력을 받을 것인데 향후 어떻게 진행될 것이며 새로운 에너지 에서 있을 수 있는 물리현상을 어느 정도 영역까지 찾을 수 있는지를 조망한다.

\section{$\mathrm{LHC}$ 가동의 향후 계획 ${ }^{[1,2]}$}

LHC는 2013년 2월까지 $8 \mathrm{TeV}$ 에서의 데이터 획득을 끝내

\section{저자약력}

김동희 교수는 미국 시라큐스대학에서 입자물리실험으로 박사(1990) 학위 를 받았다. 미국 페르미연구소에서 연구원으로 활동(1990-1992)하였으며 WCU 고에너지 충돌 물리 연구 사업단장(2009-2013)을 거쳤다. 현재 경 북대학교 물리학과 교수(1993-)이다. 주 연구 분아는 강입자 충돌을 통한 새로운 물리 현상의 탐색으로 CERN의 LHC의 CMS 실험을 수행 중에 있 다. (dkim@knu.ac.kr)

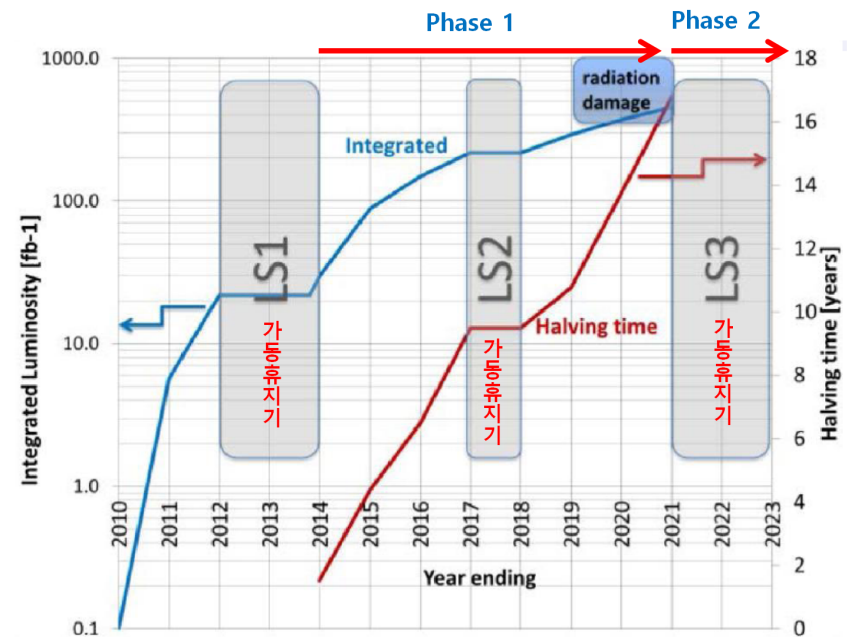

Fig. 1. LHC operation schedule for the next ten years. Total integrated luminosity before phase 2 will be $300 \mathrm{fb}^{-1}$. During the phase 1 period there is one more shutdown of the LHC to install upgrade components to the Detector. Integrated luminosity and running time to reduce by a factor of two the statistical error based on flat luminosity(halving time).

고 가동을 중단시킨 상태(그림 1에서의 LS1)에서 빔에너지를 높이기 위하여 가속기 부품을 교체하고 있다. 이 새로운 에너 지는 인류가 여태껏 성취하는 가장 높은 에너지인데다가 획득 할 데이터의 양이 기존보다 10 배 이상이기 때문에 새로운 물 리현상을 찾으려는 관점에서 가히 획기적이다. 지난 3 년여 7 , $8 \mathrm{TeV}$ 에서의 실험이 서론이었다면 지금부터 향후 10 년여 $\mathrm{LHC}$ 실험은 본론이라 할 수 있다.

예정대로라면 2014년 11월, $13 \mathrm{TeV}$ 에서의 가동이 시작되고 1년여, 데이터를 획득하게 된다. 그 후 $\mathrm{LHC}$ 의 본래 설계 에너 지인 $14 \mathrm{TeV}$ 는 2016년 초에 시작될 것으로 사료된다. 2021

\section{REFERENCES}

[1] High Energy Frontier, LHC, European Strategy for Particle Physics Symposium, Krakow, Sep. (2012).

[2] LHC Performance Workshop, "Charmonix 2012", Feb. (2012). 


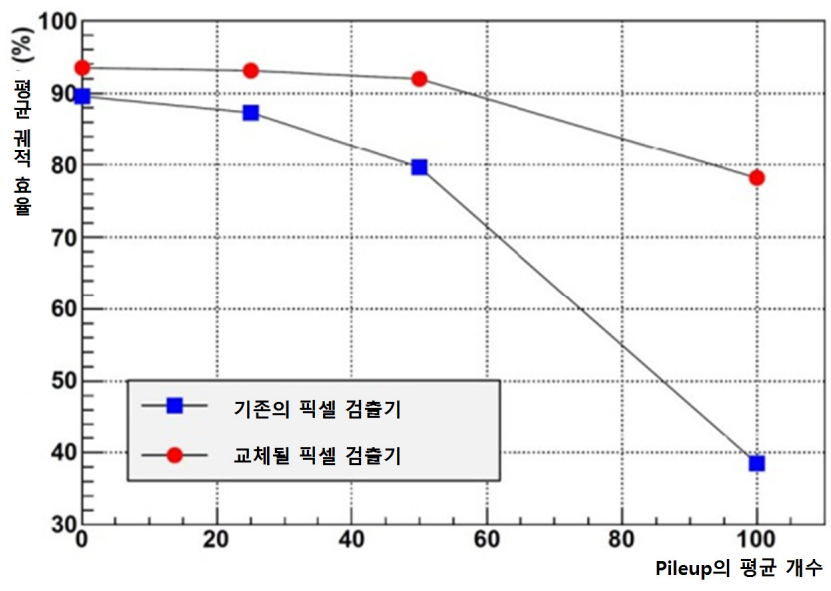

Fig. 2. Tracking Efficiencies of CMS pixel Detector according to the number of pileup. New pixel detector, that will be install at LS2 period, shows near $80 \%$ tracking efficiency while current one with $40 \%$ at 100 pileup.

년 정도까지 $14 \mathrm{TeV}$ 의 양성자-양성자 충돌 실험을 거쳐 300 $\mathrm{fb}^{-1}$ 데이터를 획득할 예정으로 있다. Phase 1 이라 불리는 이 기간 동안에 검출기의 보완을 위하여 1 년 동안 한차례 가속기 휴지 기간(LS2)이 있다. 그러므로 Phase 1 동안에 7(8) TeV에 서 획득한 양의 약 10 배로서 만약에 기존의 $7(8) \mathrm{TeV}$ 의 데이 터 획득의 속도라면 약 17 년 걸리게 되므로(그림 1에서 halving time) 가속기의 새로운 에너지에서의 작동 계획이 매우 도전적 임을 알 수가 있다.

Phase 1 이후에 Super-LHC라 불리는 가속기와 검출기의 대규모 업그레이드를 거쳐 방대한 데이터의 획득을 위한 고휘 도 환경에서의 $14 \mathrm{TeV}$ 충돌(HL-LHC: High Luminosity LHC) 실험이 2030년대 초까지 계획되어 있다. 이 기간을 phase 2 라 하는데 획득 예정의 데이터의 양은 $3000 \mathrm{fb}^{-1}$ 가 목 표로서 $\mathrm{HL}-\mathrm{LHC}$ 이전의 phase 1 의 $14 \mathrm{TeV}$ 실험에서의 데이 터 획득 양보다 10 배 이상 크다.

\section{검출기 업그레이드}

$\mathrm{LHC}$ 가속기의 새로운 빔계수(에너지, 휘도 등)에서의 작동 계획에 맞추어 검출기의 보완 ${ }^{[3]}$ 이 필요하다. $7(8) \mathrm{TeV}$ 데이터 획득 기간과 비교하여 우선 에너지가 약 2 배 커지고 획득하려 고 하는 데이터 역시 phase 1의 기간에서만 약 10배이고 phase 2 를 합하면 100 배에 이른다. 휘도가 높아지려면 순간 휘도(instantaneous luminosity)를 높여야 하므로 그만큼 검출 기가 받는 피로도는 커질 수밖에 없다. LHC의 경우는 Tevatron 과는 달리 고휘도 환경이므로 빔이 한번 충돌할 때 양성자들 이 여러 번 정면충돌이 일어나므로 실제 쓸 만한 사건(예로서 매우 높은 횡운동량 사건)을 그로부터 골라내야 하는 어려움이

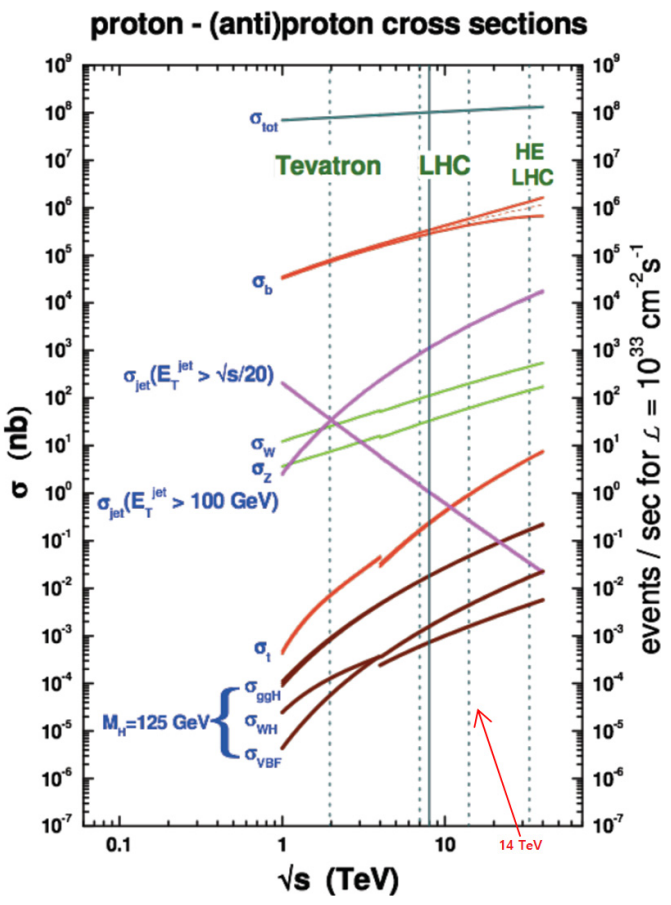

Fig. 3. Cross-sections of various decay from hadron collisions. Red arrow indicates $14 \mathrm{TeV}$ implying about 10 times higher cross-section than $8 \mathrm{TeV}$.

있다. 충돌 시 양성자들의 정면충돌이 $8 \mathrm{TeV}$ 에서 20 정도에서 새 환경에서는 100 이상으로 늘어난다. 이를 파일업(pileup)이 라 하는데 파일업이 커지므로 측정의 효율이 매우 낮아진다. 그러므로 기존의 측정 한계를 넘어서는 최적의 조건이 되기 위해서 검출기의 보완은 필수적이다.

검출기의 업그레이드는 세 번에 걸쳐 가속기 작동 휴지기에 가속기의 보완과 함께 이루어지게 된다. 검출기의 세부 종류는 $\mathrm{CMS}$ 와 ATLAS가 비록 다를지라도 기본적으로 새로운 가속기 환경에서 보완의 관점에서는 비슷하다. $\mathrm{CMS}$ 의 경우 ${ }^{[4]}$ 붕괴 입 자들의 검출 능력을 높이기 위하여 아직 많은 부분이 설치되 지 않은 전방향(forward) 영역의 세부검출기들이 LS1과 LS2 기간에 새로이 설치하고, phase에 따라 세부검출기별로 필요 한 부분을 보완한다. 특히나 고휘도 환경에서의 강한 방사능 피폭으로 인해 빔파이프를 감싸고 있는 버텍스검출기와 궤적검 출기는 $\mathrm{LHC}$ 작동 휴지기 $\mathrm{LS} 2$ 에 완전히 교체되고 3 년 뒤인 $\mathrm{HL}-\mathrm{LHC}$ 환경에서 강한 방사능 피폭 환경으로 인하여 다시 한 번 새로이 교체된다.

데이터 획득의 비율이 최소한 6 배 커지는 새로운 환경에서

\section{REFERENCES}

[3] J. Olsen, 'CMS future plans' Snowmass energy frontier workshop, July (2013).

[4] CMS upgrade week, http://CMSUP2013.desy.de, DESY June (2013). 
입자의 선별을 위한 트리거(trigger)도 발견된 힉스 입자의 질량, 결합상수 등을 좀 더 정밀하게 측정 하기 위하여 통과 허용 에너지를 낮게 유지해야 하며 그와 동시에 모든 가능한 붕괴 채널에서 새 로운 물리 현상의 발견을 최대화시키는데 주안점 을 두고 있다. 컴퓨팅의 경우도 예외가 아니어서 최소한 기존의 효율을 유지하도록 수십 페타바이 트의 방대한 데이터의 처리 능력을 가지도록 보완 한다.

\section{$14 \mathrm{TeV}$ LHC 물리}

$\mathrm{LHC}$ 는 향후 15 년여 동안 $14 \mathrm{TeV}$ 의 에너지에 서 더 많은 데이터를 획득하여 발견된 힉스입자의 성질을 좀 더 정밀하게 측정하며 더 나아가 있을 지도 모를 새로운 물리 현상의 탐색에 주력할 것 이다. 충돌에너지가 기존에 비해 2 배에 이르므로 대부분의 물 리 현상의 산란단면적이 약 10배 증가하므로 그만큼 새로운 입자의 발견 가능성이 그 어느 때보다 커졌다. 언급했듯이 이 기간은 크게 두 단계(phase 1, 2)로 나뉘어져 있다.

우선 1단계에서 초대칭모형 입자, 또는 새로운 게이지보존 등 그 외 다른 새로운 입자가 가질 수 있는 질량 영역을 기존 보다 2 배 이상 탐색할 수 있음으로 새로운 입자의 발견을 위 한 연구가 가장 활발히 진행될 것이다. 발견된 힉스입자의 질 량, 스핀, 공명의 폭, 결합상수 등 힉스입자의 성질에 대한 측 정이 한층 정확해질 것이다. 벡터-벡터 산란의 측정이 본격적 으로 이루어질 전망이다. 그 외 표준모형이 예측하는 희귀붕괴 현상의 측정 폭을 더 넓힐 수 있을 것이다.

고휘도 환경의 2 단계에서는 1 단계에서 혹 새로운 입자가 발 견되었다면 새로운 입자의 특성의 측정에 주력할 것이고 초대 칭입자, 또는 다른 여타 입자의 탐색 가능 질량 영역을 더 넓 힐 것이다. 힉스입자의 성질 등이 더욱 더 정밀하게 측정될 것 이고 힉스와 다른 기본입자의 결합상수가 $5 \%$ 이내, $8 \mathrm{TeV}$ 에 서는 전혀 측정되지 못했던 힉스들의 자체 결합상수가 $30 \%$ 정도에서 측정될 것으로 기대된다. 희귀붕괴 측정의 정밀도를 한층 높일 것으로 기대된다.

\section{힉스입자의 성질의 포괄적 이해}

발견된 입자를 힉스입자로 공식적으로 확인한 데에는 힉스입 자가 가지는 여러 물리적 특성이 실험 결과와 일치하기 때문 이다. 적어도 힉스가 다른 입자로 붕괴하는 형태 중 몇 개의 붕괴 형태는 확실히 관측이 되었고 그들의 생성률과 갈래비가
실험 오차 내에서 일치한다. 더 나아가 힉스보존이 스칼라 입 자이므로 스핀이 0 이고 패리티가 +(even)이라는 것을 통계적으 로 발견된 입자가 pseudo 스칼라가 아닌 스칼라 ${ }^{[5,6]}$ 로 밝혀졌 다.

더 나아가 힉스라면 입자가 발견된 두 개의 광자로 가는 채 널과 두 개의 $Z$ 보존으로 붕괴하는 채널 외에 다른 붕괴 채널 에서도 신호가 있다는 정황이 나와야 하나 두 개의 채널 외에 다른 채널들은 신호가 있다는 정황을 보이는 것도 있고 아직 없는 것도 있다. 힉스입자와 기본입자의 상호작용의 크기는 기 본입자의 질량의 크기에 비례하기 때문에 상대적으로 질량이 작은 뮤온, 전자 등은 $8 \mathrm{TeV}$ 에서는 상호작용의 강도가 너무 작기 때문에 검색되지 않았다.

그러므로 $14 \mathrm{TeV}$ 시대에서의 힉스입자 연구는 크게 두 가 지로 대별될 수 있는데 하나는 $8 \mathrm{TeV}$ 에서 측정된 붕괴모드와 그로부터의 질량을 더 정밀하게 측정하며 다른 하나는 산란단 면적이 너무 낮아 아직 도출되지 않았거나, 도출되었으나 통계 적으로 너무 낮은 모든 붕괴 채널을 측정하는 것이다. 새로운 에너지에서 힉스입자의 물리적 특성을 모든 면에서 정확도가 커질 것이다. 더군다나 힉스입자의 모든 붕괴 채널이 측정 가 능하며 벡터 보존 퓨전(Vector Boson Fusion: $\mathrm{VBF})$ 에 의한 과정을 거친 붕괴 현상도 모두 관측될 것이다.

그림 3에서 보는 바와 같이 CMS와 ATLAS에서 측정된 $\sigma / \sigma_{S M}$ 은 다양한 붕괴 채널에 따라 정확도가 다르지만 두 그

\section{REFERENCES}

[5] CMS collaboration, Phys. Rev. Lett. 110, 081803 (2013).

[6] ATLAS collaboration, Phys. Lett. B 726, 120 (2013). 
룹 모두 $30 \%$ 에서 $50 \%$ 수준이다. 얼핏 보기에도 $\mathrm{CMS}$ 의 $\sigma / \sigma_{S M}$ 값은 1 보다 작은 경향이며 ATLAS는 1 보다 큰 경향을 보인다. 그럼에도 두 결과의 불일치 를 애기하기에는 오차가 너무 크다. $14 \mathrm{TeV}$ 에너지에 서 $300 \mathrm{fb}^{-1}$ 의 데이터로 이 값의 정확도가 모두 $5 \%$ 내외로 줄어들 것으로 예측된다. HL-LHC의 3000 $\mathrm{fb}^{-1}$ 환경에서 $3 \%$ 이내의 정확도로 측정하려는 것이 목표이다. 또한 힉스입자 질량 영역에서 아직 피크 (peak)가 보이지 않고 여분이 존재하는 $b \bar{b}, \tau \bar{\tau}$ 등의 채널의 $8 \mathrm{TeV}$ 결과에 비교하여 새로운 에너지에서는 $b \bar{b}, \tau \bar{\tau}$ 등에서도 $5 \sigma$ 이상의 결과를 얻을 것으로 사 료되며 $\mu^{+} \mu^{-}$붕괴도 측정될 수 있을 것이다. 특히나 $\mathrm{HL}-\mathrm{LHC}$ 에서는 힉스 자신의 결합상수도 $30 \%$ 수준으 로 측정될 수 있다.
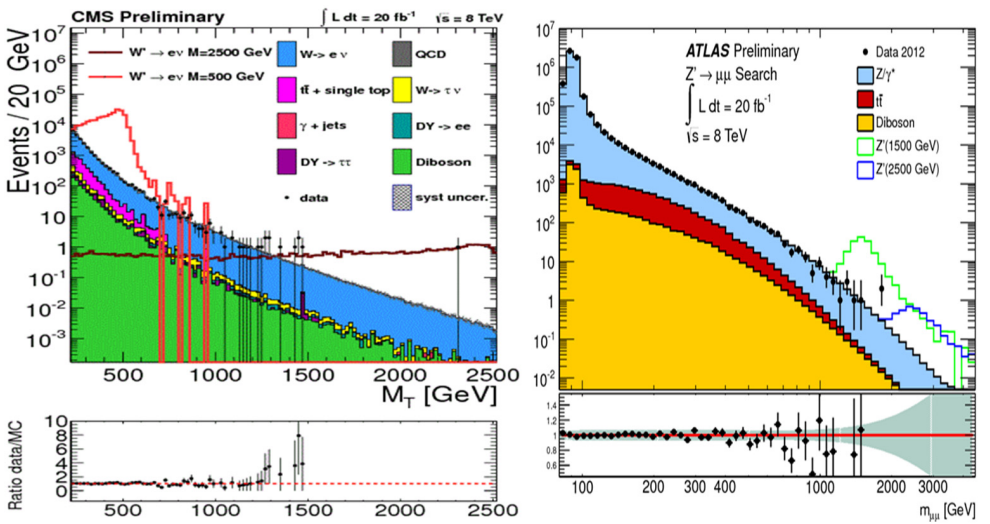

Fig. 5. Transverse mass distribution from a single electron(CMS) and dimuon invariant mass distribution(ATLAS) with full $8 \mathrm{TeV}$ data. For both, there are very high energy events while the background in the region is estimated at the level of $10^{-2}$ to $10^{-3}$. The events could be due to the statistical fluctuation but could also be the low energy tail of the real particle beyond a search region with the given energy.

\section{경입자만을 포함하는 채널에서의 새로운 현상}

실험적 관점에서 경입자의 검출의 용이성으로 경입자만으로 붕괴하는 채널들은 새로운 물리 현상을 찾는데 가장 주 탐색 대상의 하나이다. 일반적으로 충돌형 검출기들은 경입자의 측 정에 강하여 CMS와 ATLAS 실험 모두 이들 경입자를 $90 \%$ 이상의 효율을 가지고 검출해내고 있다. 물리적으로도 새로운 물리 현상이 존재한다면 입자가 나올 가능성이 가장 먼저 있 을 수 있는 채널이기 때문이다. 새로운 입자가 나타날 경우 다 른 복잡한 붕괴를 가지고 있는 채널에는 나타나고 경입자만으 로 붕괴하는 채널에는 보이지 않는 경우는 매우 드물기 때문 이다.

$\mathrm{LHC}$ 에서 양성자와 양성자의 충돌로부터 전자와 양전자 또 는 두 뮤온 등 경입자 쌍으로 붕괴 $\left(p p \rightarrow e^{+} e^{-}, \mu^{+} \mu^{-}, \tau^{+} \tau^{-}\right)$하 는 경우와 전자나 뮤온 등 하전된 경입자와 중성미자로 붕괴 $(p p \rightarrow e \nu, \mu \nu)$ 하는 경입자만으로 붕괴하는 채널은 실험적 관 점에서 매우 중요하다. 이들 붕괴 채널은 새로운 물리 현상의 발견 가능성이 있다는 판단 아래 획득된 데이터의 선별 작업 이 거의 즉각적으로 이루어지고 있다.

$8 \mathrm{TeV}$ 데이터 분석 결과 ${ }^{17,8]}$ 는 여태껏 나타나지 않았던 2 $\mathrm{TeV}$ 이상의 매우 높은 에너지에서 사건들이 있는 것처럼 보여 준다. 물론 이것이 실제 입자가 아니고 단순한 통계적 요동이 라고도 볼 수도 있지만 다른 한편으로 자연의 새로운 현상의 폭로일지도 모른다는 의구심도 있기 때문이다. 따라서 이들 채 널에 대해서 매우 세심한 주의를 기울일 필요가 있다. 더 나아 가 향후 $14 \mathrm{TeV}$ 에너지에서는 무엇이 나올지 전혀 모르는 상 황이므로 큰 기대를 걸고 있는 실정이다.

이들 경입자만으로 붕괴하는 채널은 이론적으로 해석할 수
있는 여러 모형들이 존재한다. 우선 표준모형을 간단히 확장 시킨 모형들 ${ }^{[9}$ 에서 $\mathrm{W}$ 및 $\mathrm{Z}$ 보존 외에 더 무거운 게이지 보 존이 소개된다. 예를 들어 표준모형의 Left-Handed $\mathrm{SU}(2)$ 에 Right-handed SU(2) 대칭을 부여한 Left-Right 대칭 모형에서 는 Right-handed current에 결합하는 게이지 보존이 부가적으 로 요구된다. 중성보존은 sequential $Z$ 뿐만이 아니라 $E_{6}$ 와 $\mathrm{SO}(10) \mathrm{GUT}$ 모형에서는 $Z_{\Psi}, Z_{\eta}, Z_{\chi}, Z_{I}$ 등 여럿의 중성 보존 들이 등장한다. 그 외에도 여분의 $\mathrm{U}(1)$ 게이지 대칭성을 지니 는 모형들이 많이 있으며, 초끈에서 유도되는 모형들도 일반적 으로 $\mathrm{U}(1)$ 대칭성을 많이 가진다. 즉, 여분의 게이지 입자는 새로운 물리법칙들에 자연스럽게 등장하는 입자들이다. 부가차 원(Extra Dimension: $\mathrm{ED})$ 에서도 경입자로만 붕괴하는 채널을 예측하는데 대표적으로 Warped $\mathrm{ED}$ 에서의 Randall-Sundrum graviton, ${ }^{[10]} \mathrm{LED}\left(\right.$ Large $\mathrm{ED}$ ) ${ }^{[1]}$ 에서의 $M_{S}$, split-UED(Universal $\mathrm{ED})^{[12]}$ 에서의 Kaluza-Klein W' 등이 그것이다. 그 외에 Contact Interaction ${ }^{[13]}$ 에서도 단일 경입자를 통해 구속에너지 $\Lambda$ 값을 구하는 시도가 있다.

\section{REFERENCES}

[7] CMS collaboration, Phys. Rev. D 87, 072005 (2013)

[8] ATLAS collaboration, ATLAS-CONF-2013-017 (2013).

[9] Refer P. Langacker, Physics Report 72, 185 (1981); J. L. Rosner, Phys. Rev. D 54, 1078 (1996).

[10] L. Randall and R. Sundrum, Phys. Rev. Lett. 83, 3370 (1999).

[11] N. Arkani-Hamed, S. Dlmopoulos and G. Dvali, Phys. Lett. B 429, 263 (1998).

[12] K. Kong, S. C. Park and T. G. Rizzo, JHEP 04, 081 (2010).

[13] K. Lane, F. Paige, T Skwarnicki et al., Physics Report 278, 291 (1997).

[14] twiki.cern.ch/twiki/bin/view/AtlasPublic/WebHome\#Upgrade _Projects_and_Physics_Pro. 
예로서 $\mathrm{W}^{\prime}$ 입자의 경우 $8 \mathrm{TeV}$ 모든 데이터를 적용하여 $3.35 \mathrm{TeV}$ 까지의 질량 영역을 제외시켰 고 Z'의 경우도 비슷한데 $14 \mathrm{TeV}$ 에서는 $6.5 \mathrm{TeV}$ 정도까지 탐색 ${ }^{[14]}$ 이 가능하다.

\section{초대칭 입자}

힉스입자의 발견으로 초대칭 입자의 존재 유무 가 한층 더 탄력을 받게 되었다. 물론 초대칭모형 입자 중의 뉴트랄리노(neutralino: $\widetilde{\chi_{1}^{0}}$ LSP)는 암 흑물질 후보로서도 고려되며 통일 결합 상수의 단 일화를 할 수 있다는 등 여러 측면에서 힉스 발견 이후 주목 을 받고 있는 것은 사실이다. 너무 다양한 초대칭 모형 중에 몇몇 매우 간단한 - 변수를 줄이거나 가정을 통해 단순화한 모형들은 힉스입자의 발견으로 인해 이미 제외되었고 기존의 스칼라쿼크와 글루이노를 찾는 정형화된 방법론, 즉 여러 붕괴 패턴을 찾은 다음 물리계수를 적용하여 계수들을 질량과 함께 제외시키는 방법론에서도 탈피하는 추세를 보이게 되었다.

힉스입자의 질량이 $126 \mathrm{GeV}$ 라는 것은 힉스입자가 가볍다는 뜻이다. 가벼운 힉스입자로 인해 표준모형의 톱쿼크에 대응되 는 초대칭 입자인 스칼라 톱쿼크(scalar top quark)와 버텀쿼 크에 대응되는 스칼라 버텀쿼크(scalar bottom quark) 등의 질량이 기존의 모든 가능한 질량의 영역에서 상대적으로 가벼 워야 한다는 제약을 받게 된다. 이는 매우 엄중한 귀결 ${ }^{[15]}$ 이고 가벼우면 현 상태의 에너지에서 검출기에 걸릴 수 있는 확률 이 크기 때문에 그 존재 여부를 비교적 빨리 알 수 있다. 힉스 의 발견의 영향으로 초대칭 모형이 상정하는 많은 물리계수 하에서 스칼라 쿼크와 글루이노의 탐색에서 3세대 초대칭 입 자의 탐색으로 대세가 바뀌어 버렸다.

3세대 초대칭 입자는 양성자-양성자 충돌에서 글루이노의 매 개에 의해서 생성될 수 있으며 비록 산란단면적은 많이 작으 나 3세대 초대칭 입자가 직접 생성될 수도 있다. 붕괴의 실험 적 관측 여건의 특성 상 이들은 제트와 잃어버린 에너지 및 b 입자 tagging의 방법을 통하여 탐색한다. 차아지노(chargino: $\left.\widetilde{\chi_{1}^{ \pm}}\right)$나 뉴트랄리노 $\left.\widetilde{\chi_{2}^{0}}\right)$ 또는 스칼라 경입자 쌍 등이 생성되어 다량의 경입자와 잃어버린 에너지로 붕괴하는 채널도 있다.

CMS와 ATLAS에서의 $8 \mathrm{TeV}$ 결과 ${ }^{[16-18]}$ 는 글루이노가 약 $1350 \mathrm{GeV}$ 까지 그에 따른 $\mathrm{LSP}$ 의 질량이 $650 \mathrm{GeV}$ 까지 제외 $\tilde{\mathrm{g}}-\tilde{g}$ production, $\tilde{\mathrm{g}} \rightarrow \mathrm{t} \overline{\mathrm{t}} \tilde{\chi}_{1}^{0}$

CMS Preliminary

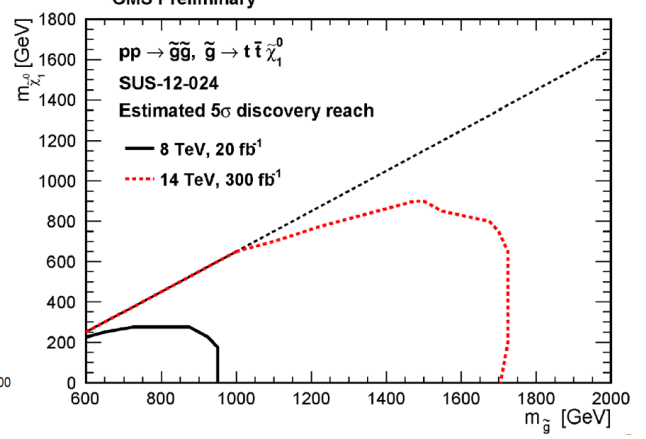

gluino mass [GeV]

Fig. 6. Gluino mass limit with various decay mode measured at CMS with $8 \mathrm{TeV}$

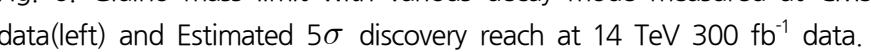

시켰다. 스칼라 톱쿼크, 차아지노 및 뉴트랄리노는 약 650 $\mathrm{GeV}$ 정도까지 제외되었다. $14 \mathrm{TeV}$ 에서 이들 초대칭 입자의 질량 탐색 영역이 모두 2 배 정도까지 커질 전망이다. 만약에 존재하여 발견을 하기 위한 $5 \sigma$ 조건하에 질량 탐색 가능 영 역은 글루이노가 $1.7 \mathrm{TeV}$, 스톱쿼크가 $750 \sim 950$, 스버텀이 $600 \sim 700$, 차아지노가 $500 \sim 600 \mathrm{GeV}$ 로서 $8 \mathrm{TeV}$ 의 결과보 다 대폭 향상될 전망이다.

\section{끝맺으며}

언급하였듯이 $\mathrm{LHC}$ 가 가동을 시작한 지는 불과 3 년여 지났 을 뿐이다. 비록 원래 목표에너지보다는 두 배 정도 낮은 에너 지인 7(8) $\mathrm{TeV}$ 에서의 가동일지라도 고난도 기술이라는 관점에 서 놀라우리만치 매우 성공적이었고 그로부터 힉스입자가 발견 되었고 그 외 수많은 새로운 결과를 쏟아내었다. 2014년 후반 기에 시작될 새로운 에너지인 $13(14) \mathrm{TeV}$ 의 가동을 통한 실험 은 그야말로 실험의 본론이라 할 수 있다. 새로운 에너지에서 약 15 년여 가동을 계획하고 있는 $\mathrm{LHC}$ 로부터 표준모형을 뛰어 넘어 인류가 몰랐던 새로운 자연 현상이 속속 도출되어 우주 에 대한 인류의 호기심이 부족하나마 충족되고 자연에 대한 이해가 고양되기를 희망한다.

\section{REFERENCES}

[15] Refer H. Baer, V. Barger and P. Huang, JHEP 109, 1205 (2012).

[16] CMS collaboration, Phys. Lett. B 725, 243-270 (2013)

[17] CMS collaboration, Phys. Rev. D 88, 052017 (2013).

[18] ATLAS collaboration, JHEP 10, 130 (2013). 